\title{
Multiobjective Order Assignment Optimization in a Global Multiple-Factory Environment
}

\author{
Rong-Chang Chen and Pei-Hsuan Hung \\ Department of Distribution Management, National Taichung University of Science and Technology, \\ No. 129, Section 3, Sanmin Road, Taichung 404, Taiwan
}

Correspondence should be addressed to Rong-Chang Chen; rcchens@nutc.edu.tw

Received 31 January 2014; Revised 15 April 2014; Accepted 18 April 2014; Published 1 June 2014

Academic Editor: Hamid Reza Karimi

Copyright (C) 2014 R.-C. Chen and P.-H. Hung. This is an open access article distributed under the Creative Commons Attribution License, which permits unrestricted use, distribution, and reproduction in any medium, provided the original work is properly cited.

\begin{abstract}
In response to radically increasing competition, many manufacturers who produce time-sensitive products have expanded their production plants to worldwide sites. Given this environment, how to aggregate customer orders from around the globe and assign them quickly to the most appropriate plants is currently a crucial issue. This study proposes an effective method to solve the order assignment problem of companies with multiple plants distributed worldwide. A multiobjective genetic algorithm (MOGA) is used to find solutions. To validate the effectiveness of the proposed approach, this study employs some real data, provided by a famous garment company in Taiwan, as a base to perform some experiments. In addition, the influences of orders with a wide range of quantities demanded are discussed. The results show that feasible solutions can be obtained effectively and efficiently. Moreover, if managers aim at lower total costs, they can divide a big customer order into more small manufacturing ones.
\end{abstract}

\section{Introduction}

To best satisfy the requirements of customers and quickly respond to changes in the market environment, some manufacturers who produce time-sensitive products, such as fashion garments or high-tech goods, have established many manufacturing sites in other countries. Global manufacturing has become a competitive strategy for many manufacturers due to the cheaper labor and raw material costs overseas. The reduction of these costs, however, is generally accompanied by longer production times. How to assign customer orders rapidly to the most suitable sites while lowering costs and shortening production times has thus become an urgent issue for global companies.

The issue mentioned above is concerned with order assignment $[1,2]$ of companies with factories spreading over the globe. Companies have to consider a number of influencing factors [3]. The first factor is related to customers' requirements, which are generally diverse in quantity. Some customers have significant changes in the order quantities which range from tens of sample products to hundreds of thousands [4]. If companies can respond to a wide range of quantities demanded, then their responsiveness [5] can be enhanced. Next, the production capacity of each plant should be considered. Due to the variation in production capacity at different plants, the processing time of an order is dependent on the plant to which it is assigned. The production capability of each site should also be considered. Production capability at each site significantly influences the fulfillment of orders. For instance, in some African countries, product quantities are limited by lower skill levels, whereas plants in some Asian countries have high-level skills to produce a variety of products. Some products requiring higher skill levels have to be produced at specific sites [4]. Therefore, using a good scheme to select proper sites is very important for global companies. The last issue that a company should consider is its objectives. What a company pursues today has become multiple objectives instead of single ones. For manufacturers who produce time-sensitive products such as fashion apparel or high-tech products that typically have a short life cycle, the shortest total production time undoubtedly is the most important objective. The main objectives for a company are to pursue the lowest cost and the shortest total production time, in order to achieve the global optimization of their 
supply chain. Multiple objectives make the order assignment problem more difficult to deal with.

Multiobjective order assignment for companies with multiple plants worldwide is very complex. It belongs to the combinatorial optimization problem, which is known to be NP-hard [6]. One effective scheme is required. A company expects to obtain practical plans soon to respond to fast changing business environment. Therefore, a heuristic algorithm such as genetic algorithm (GA) [7-11] which can provide feasible solutions in a short time is more suitable than an exact algorithm that can get optimal solutions but that also requires more computation time.

There have been a number of studies related to this issue [12-19]. However, some [13-16] focus little concern on globalized industry. On the other hand, some studies focus on single objective problems $[12,17,18]$. As mentioned before, in a now extremely competitive environment, the capability to achieve multiple objectives is a necessity for a company. To address the described issue, Chen et al. [19] considered a two-objective optimization in a global multiple-factory environment, but they did not take production time into consideration. This paper proposes an effective mechanism and uses genetic algorithm to find a solution. To prove the validity of the proposed method, real data from a famous company in Taiwan are used as the basis for some experiments. Plantrelated factors such as production capacity, manufacturing costs, material costs, and transportation costs are considered. Subsequently, MOGA (multiobjective genetic algorithm) is employed to assign orders to optimally satisfy the objectives of a company, that is, the lowest total cost and the shortest production time. Some possible solutions are generated by using the genetic algorithm. One clear advantage of the genetic algorithm is that, by its very nature, we are able to produce a number of feasible solutions, thus facilitating discussion on the merits of various decisions and supporting multiobjective decision making [20]. Therefore, the decision maker can choose the solution that best satisfies customers' requirements and also achieves the company's objectives.

The rest of this paper is organized as follows. Section 2 describes the problem. Section 3 contains the model and the method of solution. In Section 4, results and discussion are presented. Section 5 presents concluding remarks and suggestions for further studies.

\section{The Problem}

2.1. Problem Description. The order assignment issue can be briefly described as below. A company has a logistics center and many sites for production, as illustrated in Figure 1. Here, the number of production sites is represented as $m$. The logistics center aggregates customer orders demanded from anywhere in the world and divide them into several manufacturing orders (MO), the total number of which is expressed as $n$. Next, the company intends to assign $n$ MOs to $m$ production sites and once production is completed, the plant will deliver it to the place designated by customers. Main factors that a company in pursuit of "the lowest total cost" and "the shortest production time" should consider are customer demands, production capacity, production skill level, due date, manufacturing cost, material cost, and delivery cost. At the same time, companies would like to respond to a wide range of order quantities demanded, in order to gain the largest advantage under a competitive environment.

\subsection{Modeling}

2.2.1. Assumptions. To simplify the problem, some assumptions are made.

(1) A customer order can be divided into several MOs. Each MO produces only one product and can be fulfilled only at a manufacturing site.

(2) Each product is composed of some kinds of raw materials. The related information on raw material is known.

(3) Each kind of raw material is provided by only one supplier.

(4) The production capacity of a manufacturing site is stable and constant. That is, the production capacity is known and fixed, but different manufacturing sites may have different capacities.

(5) The production type is MTO (make to order). Thus, there is no inventory. The quantity demanded for each product is known; there is no stock and no production in advance.

(6) Due dates of orders are known and fixed.

(7) The material cost, manufacturing cost, delivery cost, and order delay cost are known. The mode of transportation is by sea or by land, so the transportation cost can be estimated. The inbound tax on raw material and inbound transportation cost are included in the material cost. Similarly, the manufacturing cost includes the labor cost and the manufacturing overhead. The delivery cost includes the outbound transportation cost and tariff.

(8) The transportation modes from a raw material supplier to a manufacturing site and from a manufacturing site to the destination are known. Therefore, the transportation cost is known if the origin and the destination are given.

(9) Lack of material is negligible.

2.2.2. Formulation. For easy description, some symbols are defined as shown in abbreviation section.

The first objective that global companies take into account is the total cost, which can be expressed as follows:

Total cost $=$ material cost (includes direct material cost, inbound tax, and inbound transportation cost) + manufacturing cost (includes labor cost and manufacturing overhead) 


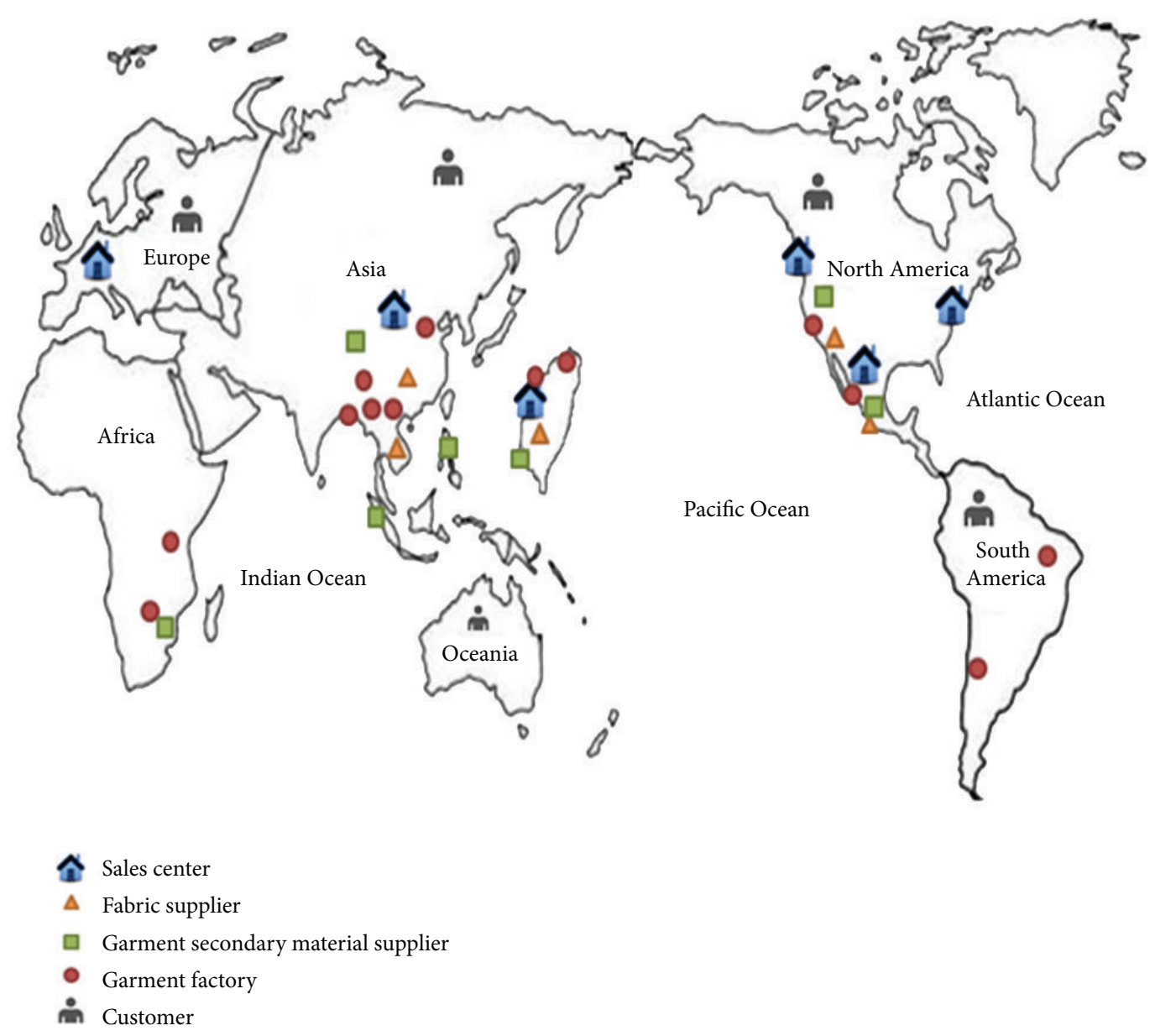

FIGURE 1: A schematic diagram of the deployment of a global garment company [4].

+ delivery cost (includes outbound transportation cost and tariff) + order delay cost:

$$
\begin{aligned}
\min Z_{1}= & \sum_{i} \sum_{j} c_{j}^{\mathrm{RM}} Q_{i j}^{\mathrm{RM}}+\sum_{i} \sum_{k} x_{i k} c_{k}^{\mathrm{MANU}} \frac{Q_{i}^{\mathrm{FG}}}{S_{k}} \\
& +\sum_{i} \sum_{k} \sum_{h} x_{i k} z_{k h} c_{k h}^{\mathrm{DELIV}} Q_{i h}^{\mathrm{FG}}+\sum_{i} c_{i}^{\mathrm{DELAY}} D_{i} .
\end{aligned}
$$

Note that in (1), the final term is the cost caused by order delay. This cost arises in some industries such as the garment sector. In practice, some companies will be asked to pay a penalty if an order is delayed. For example, the penalty rate is about $3 \%-5 \%$ of the transaction amount for some garment companies. This term is related to due dates. Some might argue: why not using due dates (such as on-time delivery rate) as an objective? One advantage of using the delay cost over using the due date as an objective is that the former provides a more accurate calculation on delayed days. As an example shown in Table 1 and Figure 2, suppose that the number of MOs is 10 and the due date for each $\mathrm{MO}$ is 5 days. Two different solutions $(E$ and $F$ ) are obtained. The on-time delivery rates for solutions $E$ and $F$ are 0.9 and 0.8 , respectively, indicating that solution $E$ is better than solution
TABLE 1: The comparison between due dates and delayed days based objectives.

\begin{tabular}{lcc}
\hline Solution & $\begin{array}{c}\text { On-time } \\
\text { delivery rate }\end{array}$ & $\begin{array}{c}\text { Total delayed } \\
\text { days }\end{array}$ \\
\hline $\begin{array}{l}E \text { (upper chart in } \\
\text { Figure 2) based on due } \\
\text { dates }\end{array}$ & $90 \%$ & 5 \\
$\begin{array}{l}F \text { (lower chart in } \\
\text { Figure 2) based on } \\
\text { delayed days }\end{array}$ & $80 \%$ & 3 \\
\hline
\end{tabular}

$F$. However, the total delayed days for solution $E$ is 5 and for solution $F$ is 3, conversely showing that solution $F$ is better than solution $E$. For manufacturers who produce timesensitive products such as fashion garments or high-tech goods, an objective based on the number of delayed days might be more suitable than one based on due dates.

Another important objective for global companies to consider is total production time. If an order can be finished within a shorter time, then the lead time can be reduced and the company has more time to deliver the products. For 


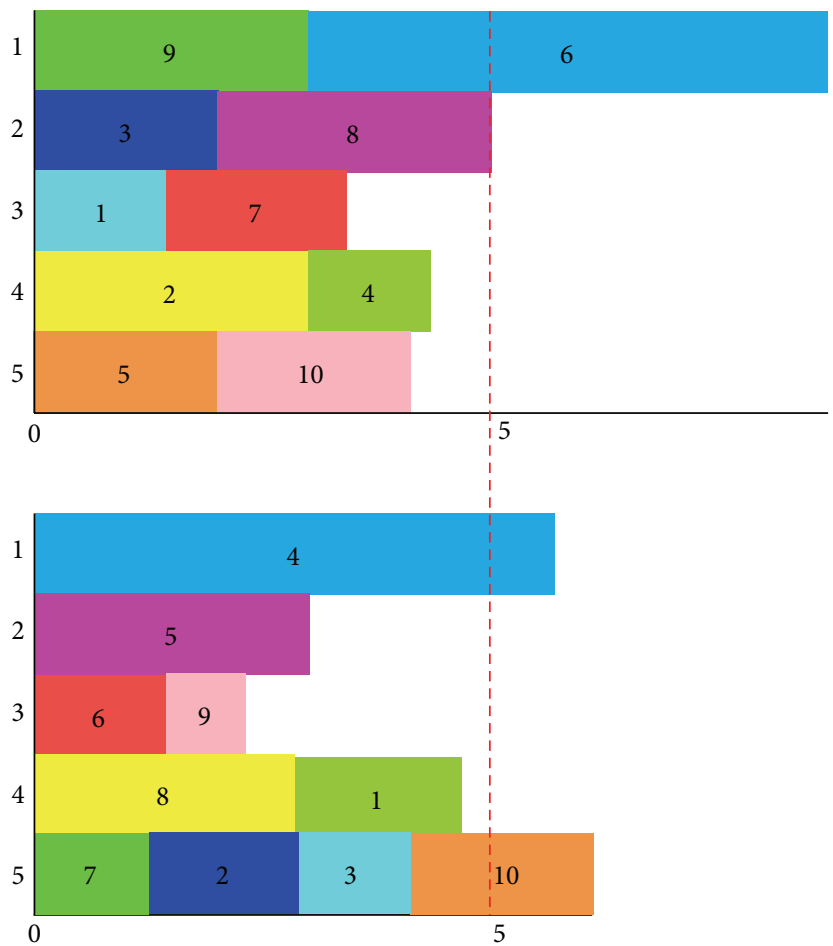

FIGURE 2: Illustration of two different solutions for comparison. The dashed line indicates the due date.

time-sensitive products, the achievement of this objective is a necessity:

$$
\min Z_{2}=\sum_{i} \sum_{k} x_{i k} \frac{Q_{i}^{\mathrm{FG}}}{S_{k}} .
$$

The constraints to be considered are

$$
\begin{gathered}
\sum_{k} x_{i k}=1, \quad \forall i \\
\sum_{i} x_{i k} S_{i} \leq S_{k}, \quad \forall k \\
x_{i k}= \begin{cases}1 & \text { if } \mathrm{MO} i \text { is assigned to site } k, \\
0 & \text { otherwise. }\end{cases}
\end{gathered}
$$

Equation (3) requires each MO to be assigned to only one manufacturing site, while (4) requires that the necessary capacity to finish products must not be greater than the capacity of each manufacturing site. $x_{i k}$ is the decision variable. As indicated in (5), $x_{i k}$ is either 0 or 1.

\section{The GA Structure}

This paper employs MOGA as a tool to find solutions. Detailed description of the GA structure is introduced in the following.

\begin{tabular}{|c|c|c|c|c|c|c|c|c|}
\hline $\mathrm{MO}$ & 1 & 2 & 3 & 4 & 5 & 6 & $\ldots$ & $n$ \\
\hline Site & 2 & 5 & 3 & 4 & 1 & 5 & $\ldots$ & 1 \\
\hline
\end{tabular}

(1) Encoding. Each chromosome represents a solution, which is comprised by some genes. To implement GA, chromosomes must be encoded first. A simple and efficient encoding
FIGURE 3: Representation of a chromosome.

method is used in this paper. The sequence of genes from left to right indicates the index number of MO. The value of a gene (alleles) stands for the index number of a manufacturing site. For example, MO " 1 " is assigned to site " 2 " and MO " 2 " is assigned to site " 5 ," as illustrated in Figure 3.

(2) Initial Solutions and Calculation of Fitness Values. The initial population is generated at random. In general, the larger the population is, the wider the search range will be. A larger population is likely to obtain better fitness values. However, the computation time for a larger population is increased.

The evaluation of a solution is performed by calculation of the fitness value of a chromosome. In this paper, the calculation is based on the total cost and the total production time. Better fitness values are retained and the best ones are chosen as the Pareto solutions, which are nondominated by other chromosomes. An efficient scheme proposed by Fonseca and Fleming is called FFGA [21], as indicated in Figure 4. By this scheme, the evolutionary time can be reduced. Let $G_{i}$ represent a chromosome at generation $t$ which is dominated 


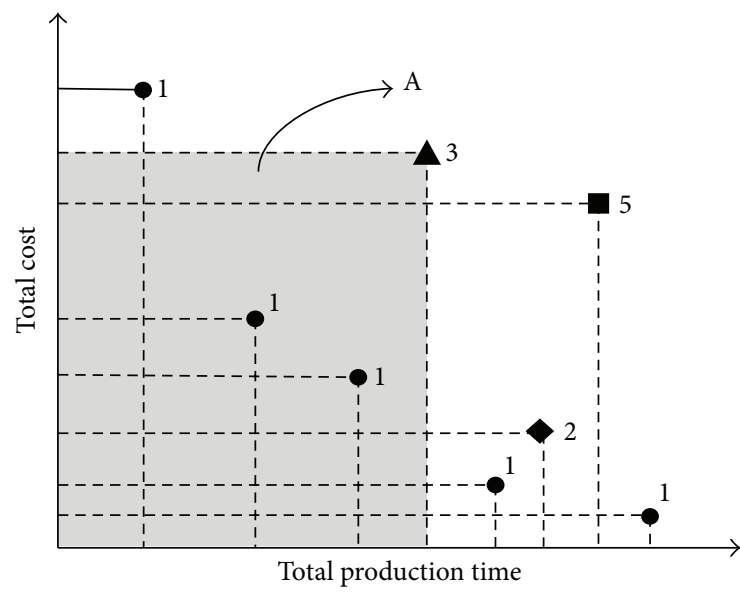

FIgURE 4: Illustration of the FFGA algorithm.

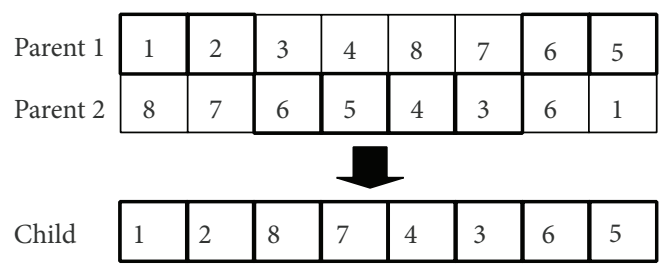

FIGURE 5: Illustration of partially matched crossover.

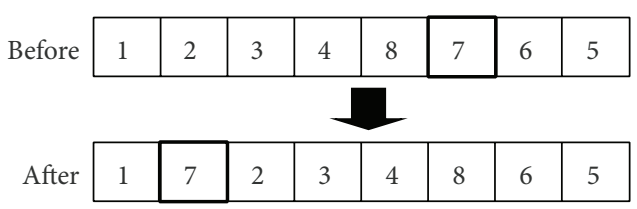

FIGURE 6: Illustration of insertion mutation. by $p_{i}^{(t)}$ individuals in the current generation. Then the rank of the individual at generation $t$ can be expressed as [21]

$$
\operatorname{rank}\left(G_{i}, t\right)=1+p_{i}^{(t)}
$$

FFGA sorts the fitness values of chromosomes in the population. Each chromosome is ranked by the number of chromosomes which dominate it according to the fitness values. The number plus one is set to be the rank of a chromosome. The more a chromosome is dominated by others, the larger value its rank is. In contrast, if a chromosome does not have others which dominate it, according to (6), it is assigned rank 1 . The one which is not dominated by anyone is designated as rank " 1 " and is collected into the Pareto set; the one dominated by two chromosomes is designated as rank " 3 " (see chromosome A in Figure 4). This makes the ranking process of chromosomes more efficient and shortens the evolutionary time.

(3) Selection and Reproduction. The modified Roulette wheel selection method is applied to select chromosomes. First, all the chromosomes' fitness values are calculated and then sorted. The larger the fitness value is, the lower the priority is. For example, if there are 20 chromosomes and their fitness values are 1 to 20 , respectively, then the chromosome with a fitness value of 1 will have the probability of $20 /(1+2+$ $3+\cdots+20)$, the chromosome with a fitness value of 2 will have the probability of $19 /(1+2+3+\cdots+20)$, and the like. In other words, superior parent chromosomes have more opportunities to be selected into next generation.

(4) Crossover. This study employs partially matched crossover to avoid repeating. As Figure 5 shows, two points of crossover are chosen at random, which will divide parent generations into three parts, respectively. The child chromosome will grab the first and third parts of parent chromosome 1 and the second part of parent chromosome 2. At the same time, the program checks whether the values of genes from parent chromosomes are repeated or not. If they are repeated, skip the repeated gene value and fill in a new value. This step will not end until all crossovers have been done.

(5) Mutation. This study adopts the insertion mutation method to mutate. A point is randomly chosen as an insertion point and a gene is chosen to insert. As Figure 6 shows, the sixth gene is chosen and the second position is an insertion point. The rest of the genes from and after the second gene are moved to the right. The insertion mutation method can avoid the repetition of a number, which represents an unfeasible solution.

(6) Creating Next Generation. To create the next generation, the tournament selection method is used. A gene pool is set up to store chromosomes. Two chromosomes are then chosen at random and compared with each other. If the fitness value of a chromosome is superior to that of a counterpart chromosome, then the chromosome is stored into the pool and used to generate the child chromosome.

(7) Termination. A number of ways can be used to terminate the program. The termination condition in this study is the achievement of a preassigned number of evolution generations set by the user. If the generation number is reached, the program will stop running and the solutions will be output. To obtain better solutions, multiple trials are suggested if the initial population is generated randomly.

\section{Results and Discussion}

This paper employs MOGA to find solutions. In addition, the Brutal-force method (BFM, or exhaustion method), which can obtain the optimal solution, is used to evaluate the performance of the MOGA program. The comparison of these two methods is shown in Section 4.1. Influences of genetic parameters are discussed in Section 4.2. Next, the influences of plant amount and order amount on the order assignment are introduced. Section 4.3 discusses the results concerning orders with wide ranges of quantities demanded. Finally, the reassignment of orders is addressed. 
The program was run in a $\mathrm{PC}$ with an operating system of Windows XP Professional SP2. The CPU is Intel Core 2 at $2.6 \mathrm{GHz}$ and the RAM is $1 \mathrm{~GB}$.

4.1. Data Input and Validation of MOGA. To evaluate the effectiveness of the proposed approach, real data from a famous garment company in Taiwan are used as a base to perform some experiments. The base case is set as follows: five garment plants and eight end products. The plants are in Taiwan (A and B plants), China, Vietnam, and the USA. Products are classified into four types: shirt, skirt, pants, and overcoat. Each one has two styles. Therefore, there are eight types of finished products, which are assigned numbers from one to eight, respectively. Input data of the numerical examples for the base case are shown in Tables 2, 3 and 4.

The data concerning MOs include its number, quantity demanded, due date, daily cost for delay, the arrival destination, and the index number of finished products. The plantrelated data include production capacities and manufacturing costs. Each plant has a monthly capacity and a daily capacity.

For easy description, we designate the number of generation as $N_{g}$, the population size as Pop, the crossover rate as $R_{c}$, the mutation rate as $R_{m}$, and the coefficient of variation as $C_{v}$. Each case was run 30 times to evaluate the GA program.

BFM is an exact algorithm that can obtain optimal solutions. If the result from MOGA is near or equal to that from BFM, then the correctness of MOGA developed in this study can be supported. On the other hand, computation time is one of the performance indices that can evaluate the efficiency of the approach. The shorter the computation time is, the faster a decision can be made.

As for genetic parameters, the generation numbers $N_{g}$ are changed from 50 to 500; the population sizes Pop are set to be 200 and 500 . The crossover rate $R_{c}$ is set to be 0.5 and the mutation rate $R_{m}$ is 0.05 at the base case. The results are summarized in Table 5. From experimental results we may find that MOGA can get good workable solutions. The accuracy for each case is over $96 \%$, even to $100 \%$. The accuracy is defined as (based on total cost):

$$
\begin{aligned}
\text { Accuracy }=\{1 & \left.-\left|\frac{\text { MOGA solution }- \text { BFM solution }}{\text { BFM solution }}\right|\right\} \\
& \times 100 \%
\end{aligned}
$$

The comparison of the computation time between MOGA and BFM is shown in Figure 7. As the number of MO increases from 8 to 13, the computation times of MOGA and BFM differ increasingly. When the number of MOs is over 11, the difference rapidly increases. Though BFM can get optimal results, the required computation time exceeds 10 hours, as the MO number is over 13. When the number of MOs becomes larger, the computation time may be over a hundred days. In practice, managers hope to get a reasonable result in a short time. BFM cannot satisfy their needs. On the contrary, by using MOGA as an analytical tool, they can get good results within seconds. It is very efficient, making the order assignment mechanism more practical.

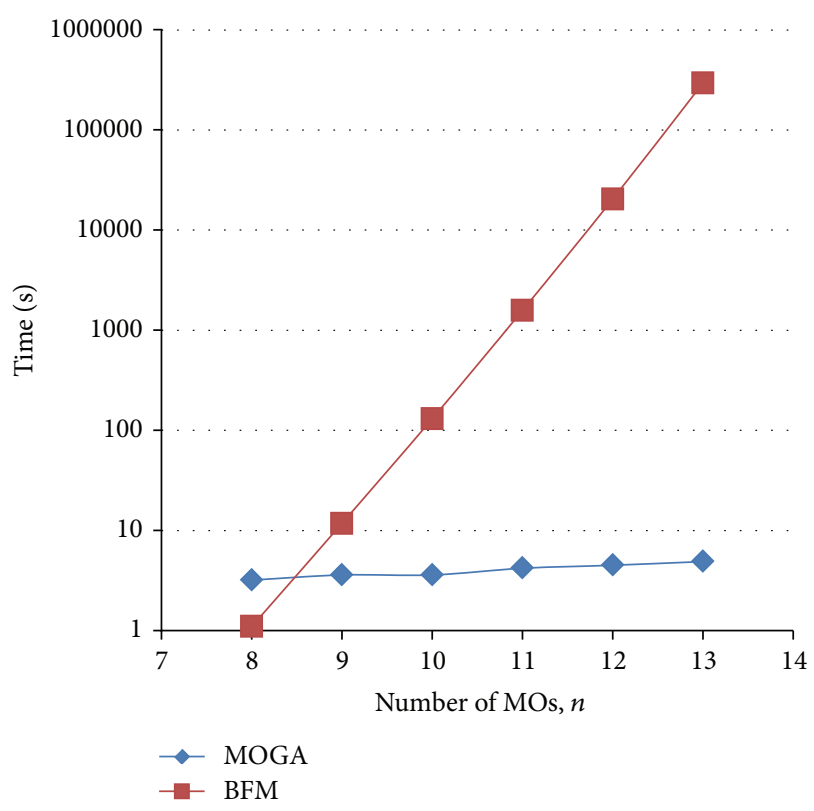

FIGURE 7: Comparison of the computation times between MOGA and BFM.

4.2. Influences of Genetic Parameters. There are four important genetic parameters when using MOGA: generation number, population size, crossover rate, and mutation rate. At the base case, there are ten MOs, eight types of products, and five plants. The crossover rate and the mutation rate are set to be 0.9 and 0.01 , respectively. The number of generation is set to be $50,100,200,300$, and 500 . The number of population is set to be 200 and 500. The MOGA program randomly creates an initial population. The results, therefore, are different by random nature. To investigate the performance of the MOGA program, each case was run with 30 trials.

When the generation number and population size equal $500 * 200$ and $500 * 500$, it is easier to obtain good results by MOGA, as shown in Table 6 . Generally, the coefficient of variation falls between 0.01 and 0.04 , indicating that the MOGA program is stable. However, from Figure 8 we may see that the computation time for the latter is about triple that of the former. Thus, this study uses $500 * 200$ to perform the following tests.

To understand the influences of the crossover rate and mutation rate, the generation number is fixed at 500 and the population size is fixed at 200. Crossover rates are then changed from 0.5 to 0.9 with an increase of 0.1 each time; mutation rates are changed from 0.01 to 0.05 . When the mutation rate is 0.05 , the results are quite stable; when the crossover rate is 0.5 and the mutation rate is 0.05 , coefficients of variation $C_{v}$ are between 0.006 and 0.028 . As compared to the result from BFM, the accuracy is $98.07 \%$ to $99.98 \%$, showing that these parameter values can give quite good results.

4.3. Influences of Changes in Plant Number and Order Quantity. As Figure 9 illustrates, the total cost increases when the total production time decreases. However, the average cost 
TABLE 2: Input data related to manufacturing orders for the base case.

\begin{tabular}{lccccc}
\hline MO & Demand (piece) & Due date (day) & Delayed cost (NTD/day) & Destination & Product number \\
\hline 1 & 13,500 & 1 & 10,000 & 2 & 7 \\
2 & 28,800 & 5 & 20,000 & 4 & 5 \\
3 & 30,000 & 2 & 50,000 & 2 & 5 \\
4 & 23,100 & 3 & 38,500 & 2 & 6 \\
5 & 13,500 & 2 & 32,500 & 3 & 3 \\
6 & 20,100 & 4 & 28,000 & 3 & 6 \\
7 & 16,800 & 1 & 12,500 & 3 & 3 \\
8 & 7,500 & 5 & 17,500 & 3 & 2 \\
9 & 10,500 & 3 & 33,000 & 2 & 1 \\
10 & 19,800 & & & 3 \\
\hline
\end{tabular}

TABLE 3: Input data related to manufacturing sites for the base case.

\begin{tabular}{lcc}
\hline Site & Capacity (piece/day) & Capacity (piece/month) \\
\hline 1 & 7,000 & 210,000 \\
2 & 7,000 & 210,000 \\
3 & 10,000 & 300,000 \\
4 & 16,000 & 480,000 \\
5 & 10,000 & 300,000 \\
\hline
\end{tabular}

TABLE 4: Sites eliminated because of unsuitable production skill levels.

\begin{tabular}{lc}
\hline MO & Eliminated sites \\
\hline 1 & $3,4,5$ \\
2 & $1,2,3$ \\
3 & 5 \\
$4-10$ & None \\
\hline
\end{tabular}

per plant decreases as the total production time decreases. When the plant number is changed, there is no great change in the coefficient of variation, which falls between 0.0018 and 0.0146 . This indicates that changes in plant number do not affect the stability of the GA program.

If the plant number increases, what influences will have on order assignment is worth discussing. To address this, some experiments are performed. The experiments performed here consider the cost of a new plant. Figure 9 shows the variation of the optimal total cost and total production time with the number of plants. With an increase in plant number, though the extra cost for a new plant is added, the total production time and total cost decrease. The computation time increases linearly with the number of plants.

After a company receives orders from all over the world, their logistics center will gather together all the customer orders and then assign them. In practice, the range of order quantity changes a lot and the amount of different customers' demands also varies. Wal-Mart, as an example, may have up to ten thousand, even hundreds of thousands of products demanded. However, only several sample products are needed for factory owners. When the quantity of an order demanded is over hundred thousand, to enhance the

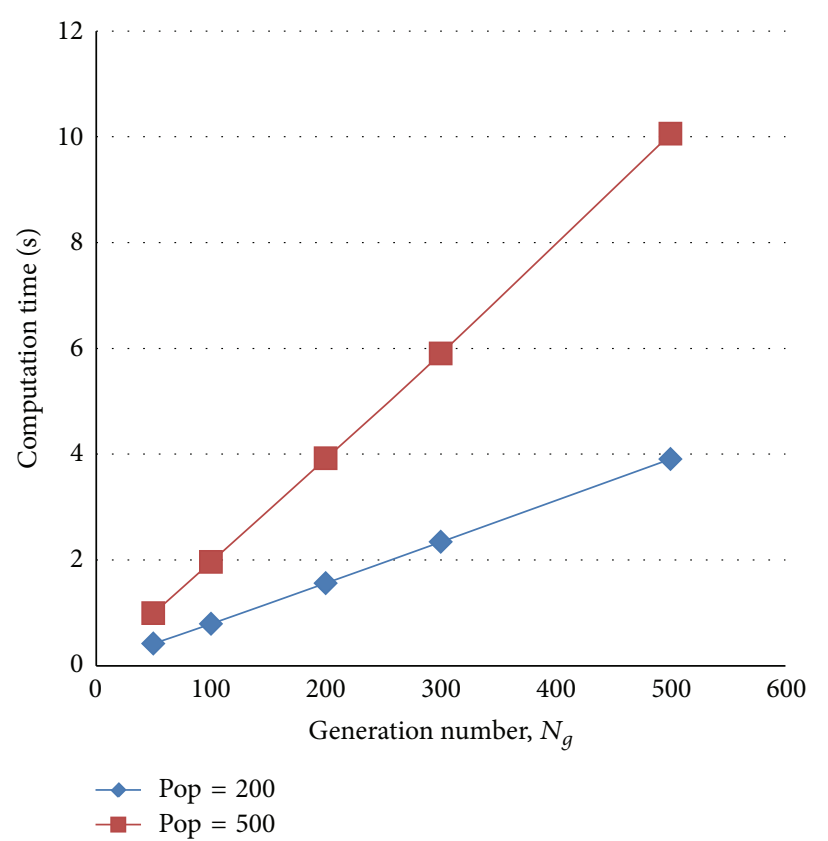

FIGURE 8: Variations of computation times with different generation numbers and population numbers.

capacity utilization rate or to balance the production loads between plants, an additional manual operation for order assignment is considered. To utilize the production capacity properly, a company may divide a big order into several smaller ones. This process is called division. If there is no process of division, it will cause some plants to be left unused and some other plants to be insufficient in production capacity. Consequently, companies should consider the capacity utilization (the percentage of the capacity that was used to the available capacity) and on-time delivery rate (the percentage of the number of on-time delivery orders to the total number of orders) as well when aiming at the shortest total production time and minimal total cost.

To investigate the influences of such a wide range of quantities demanded on the order assignment, the quantities of orders are set between 80 and 200,000 and divided on average into $10,15,20,25$, and 30 smaller orders. The 
TABLE 5: Comparison of MOGA results with those by BFM.

\begin{tabular}{|c|c|c|c|c|c|c|}
\hline$N_{g} *$ Pop & $\begin{array}{c}\text { Total Production } \\
\text { time (day) }\end{array}$ & $\begin{array}{c}\text { Total cost by } \\
\text { MOGA }\end{array}$ & $C_{v}$ & $\begin{array}{c}\text { Total cost by } \\
\text { BFM }\end{array}$ & Accuracy (\%) & Average computation time (sec) \\
\hline \multirow{4}{*}{$50 * 200$} & 27 & $33,768,890$ & 0.016 & $33,410,860$ & 98.93 & \multirow{4}{*}{0.418} \\
\hline & 28 & $33,046,345$ & 0.020 & $32,566,915$ & 98.53 & \\
\hline & 29 & $33,061,395$ & 0.013 & $32,519,485$ & 98.33 & \\
\hline & 30 & $33,264,065$ & 0.007 & $32,408,030$ & 97.36 & \\
\hline \multirow{4}{*}{$100 * 200$} & 27 & $33,668,865$ & 0.022 & $33,410,860$ & 99.23 & \multirow{4}{*}{0.790} \\
\hline & 28 & $33,064,945$ & 0.014 & $32,566,915$ & 98.47 & \\
\hline & 29 & $32,979,000$ & 0.013 & $32,519,485$ & 98.59 & \\
\hline & 30 & $33,176,050$ & 0.008 & $32,408,030$ & 97.63 & \\
\hline \multirow{4}{*}{$200 * 200$} & 27 & $33,890,290$ & 0.018 & $33,410,860$ & 98.57 & \multirow{4}{*}{1.561} \\
\hline & 28 & $33,393,335$ & 0.018 & $32,566,915$ & 97.46 & \\
\hline & 29 & $33,075,020$ & 0.013 & $32,519,485$ & 98.29 & \\
\hline & 30 & $33,075,060$ & 0.009 & $32,408,030$ & 97.94 & \\
\hline \multirow{4}{*}{$300 * 200$} & 27 & $33,668,865$ & 0.018 & $33,410,860$ & 99.23 & \multirow{4}{*}{2.338} \\
\hline & 28 & $32,834,345$ & 0.017 & $32,566,915$ & 99.18 & \\
\hline & 29 & $32,760,385$ & 0.018 & $32,519,485$ & 99.26 & \\
\hline & 30 & $33,143,460$ & 0.016 & $32,408,030$ & 97.73 & \\
\hline \multirow{4}{*}{$500 * 200$} & 27 & $33,654,765$ & 0.014 & $33,410,860$ & 99.27 & \multirow{4}{*}{3.907} \\
\hline & 28 & $32,566,915$ & 0.023 & $32,566,915$ & 100.00 & \\
\hline & 29 & $33,012,990$ & 0.011 & $32,519,485$ & 98.48 & \\
\hline & 30 & $33,564,380$ & 0.005 & $32,408,030$ & 96.43 & \\
\hline \multirow{4}{*}{$50 * 500$} & 27 & $33,659,265$ & 0.019 & $33,410,860$ & 99.26 & \multirow{4}{*}{0.991} \\
\hline & 28 & $33,085,945$ & 0.018 & $32,566,915$ & 98.41 & \\
\hline & 29 & $32,579,885$ & 0.016 & $32,519,485$ & 99.81 & \\
\hline & 30 & $32,945,955$ & 0.016 & $32,408,030$ & 98.34 & \\
\hline \multirow{4}{*}{$100 * 500$} & 27 & $33,900,290$ & 0.017 & $33,410,860$ & 98.54 & \multirow{4}{*}{1.961} \\
\hline & 28 & $33,096,345$ & 0.022 & $32,566,915$ & 98.37 & \\
\hline & 29 & $32,559,485$ & 0.015 & $32,519,485$ & 99.88 & \\
\hline & 30 & $32,923,960$ & 0.009 & $32,408,030$ & 98.41 & \\
\hline \multirow{4}{*}{$200 * 500$} & 27 & $33,653,865$ & 0.024 & $33,410,860$ & 99.27 & \multirow{4}{*}{3.916} \\
\hline & 28 & $33,045,945$ & 0.018 & $32,566,915$ & 98.53 & \\
\hline & 29 & $32,539,485$ & 0.027 & $32,519,485$ & 99.94 & \\
\hline & 30 & $33,030,060$ & 0.018 & $32,408,030$ & 98.08 & \\
\hline \multirow{4}{*}{$300 * 500$} & 27 & $33,648,865$ & 0.018 & $33,410,860$ & 99.29 & \multirow{4}{*}{5.898} \\
\hline & 28 & $32,983,840$ & 0.017 & $32,566,915$ & 98.72 & \\
\hline & 29 & $32,997,990$ & 0.014 & $32,519,485$ & 98.53 & \\
\hline & 30 & $33,114,460$ & 0.011 & $32,408,030$ & 97.82 & \\
\hline \multirow{4}{*}{$500 * 500$} & 27 & $33,644,265$ & 0.015 & $33,410,860$ & 99.30 & \multirow{4}{*}{10.052} \\
\hline & 28 & $33,085,945$ & 0.020 & $32,566,915$ & 98.41 & \\
\hline & 29 & $33,179,515$ & 0.014 & $32,519,485$ & 97.97 & \\
\hline & 30 & $32,822,455$ & 0.016 & $32,408,030$ & 98.72 & \\
\hline
\end{tabular}

influences of the division number $(C)$ on the production time, the production cost, the capacity utilization, and the on-time delivery rate are examined. Results from the experiments show that although the division process will lead to an increase in the total production time, it helps enhance the capacity utilization. In addition, no matter whether an order is divided or not, the on-time delivery rates are ranging from $88 \%$ to $96 \%$.

For the division numbers $C=25$ and $C=30$, the results are crossed, as shown in Figure 10. On the right side of the crossed point, the higher the division number is, the smaller the total cost will be. If managers aim at decreasing the total 
TABLE 6: Variations of solutions with different crossover rates and different mutation rates.

\begin{tabular}{|c|c|c|c|c|c|c|}
\hline$R_{c} * R_{m}$ & Production time (day) & Total cost by MOGA & $C_{v}$ & Total cost by BFM & Accuracy (\%) & Average computation time (sec) \\
\hline \multirow{4}{*}{$0.9 * 0.01$} & 27 & $33,644,265$ & 0.021 & $33,410,860$ & 99.30 & \multirow{4}{*}{3.901} \\
\hline & 28 & $32,833,315$ & 0.023 & $32,566,915$ & 99.18 & \\
\hline & 29 & $32,800,385$ & 0.014 & $32,519,485$ & 99.14 & \\
\hline & 30 & $33,087,465$ & 0.014 & $32,408,030$ & 97.90 & \\
\hline \multirow{4}{*}{$0.9 * 0.02$} & 27 & $33,425,860$ & 0.022 & $33,410,860$ & 99.96 & \multirow{4}{*}{3.899} \\
\hline & 28 & $32,973,440$ & 0.019 & $32,566,915$ & 98.75 & \\
\hline & 29 & $32,539,485$ & 0.017 & $32,519,485$ & 99.94 & \\
\hline & 30 & $32,885,040$ & 0.009 & $32,408,030$ & 98.53 & \\
\hline \multirow{4}{*}{$0.9 * 0.03$} & 27 & $33,774,290$ & 0.012 & $33,410,860$ & 98.91 & \multirow{4}{*}{3.903} \\
\hline & 28 & $32,828,945$ & 0.024 & $32,566,915$ & 99.20 & \\
\hline & 29 & $32,997,990$ & 0.016 & $32,519,485$ & 98.53 & \\
\hline & 30 & $33,161,450$ & 0.010 & $32,408,030$ & 97.68 & \\
\hline \multirow{4}{*}{$0.9 * 0.04$} & 27 & $33,768,890$ & 0.018 & $33,410,860$ & 98.93 & \multirow{4}{*}{3.899} \\
\hline & 28 & $33,056,345$ & 0.020 & $32,566,915$ & 98.50 & \\
\hline & 29 & $32,979,000$ & 0.016 & $32,519,485$ & 98.59 & \\
\hline & 30 & $33,114,460$ & 0.011 & $32,408,030$ & 97.82 & \\
\hline \multirow{4}{*}{$0.9 * 0.05$} & 27 & $33,677,260$ & 0.019 & $33,410,860$ & 99.20 & \multirow{4}{*}{3.899} \\
\hline & 28 & $32,983,840$ & 0.017 & $32,566,915$ & 98.72 & \\
\hline & 29 & $32,539,485$ & 0.014 & $32,519,485$ & 99.94 & \\
\hline & 30 & $33,170,355$ & 0.008 & $32,408,030$ & 97.65 & \\
\hline \multirow{4}{*}{$0.8 * 0.01$} & 27 & $33,668,865$ & 0.020 & $33,410,860$ & 99.23 & \multirow{4}{*}{3.463} \\
\hline & 28 & $33,778,930$ & 0.017 & $32,566,915$ & 96.28 & \\
\hline & 29 & $32,965,995$ & 0.015 & $32,519,485$ & 98.63 & \\
\hline & 30 & $32,896,955$ & 0.014 & $32,408,030$ & 98.49 & \\
\hline \multirow{4}{*}{$0.8 * 0.02$} & 27 & $33,768,890$ & 0.019 & $33,410,860$ & 98.93 & \multirow{4}{*}{3.461} \\
\hline & 28 & $33,060,345$ & 0.018 & $32,566,915$ & 98.48 & \\
\hline & 29 & $33,061,395$ & 0.014 & $32,519,485$ & 98.33 & \\
\hline & 30 & $33,087,465$ & 0.012 & $32,408,030$ & 97.90 & \\
\hline \multirow{4}{*}{$0.8 * 0.03$} & 27 & $33,659,265$ & 0.025 & $33,410,860$ & 99.26 & \multirow{4}{*}{3.459} \\
\hline & 28 & $33,219,365$ & 0.011 & $32,566,915$ & 98.00 & \\
\hline & 29 & $33,075,020$ & 0.011 & $32,519,485$ & 98.29 & \\
\hline & 30 & $32,669,940$ & 0.014 & $32,408,030$ & 99.19 & \\
\hline \multirow{4}{*}{$0.8 * 0.04$} & 27 & $33,677,260$ & 0.026 & $33,410,860$ & 99.20 & \multirow{4}{*}{3.460} \\
\hline & 28 & $32,983,840$ & 0.024 & $32,566,915$ & 98.72 & \\
\hline & 29 & $32,941,010$ & 0.018 & $32,519,485$ & 98.70 & \\
\hline & 30 & $33,392,075$ & 0.007 & $32,408,030$ & 96.96 & \\
\hline \multirow{4}{*}{$0.8 * 0.05$} & 27 & $33,416,260$ & 0.028 & $33,410,860$ & 99.98 & \multirow{4}{*}{3.460} \\
\hline & 28 & $32,838,715$ & 0.014 & $32,566,915$ & 99.17 & \\
\hline & 29 & $33,176,000$ & 0.013 & $32,519,485$ & 97.98 & \\
\hline & 30 & $33,384,470$ & 0.009 & $32,408,030$ & 96.99 & \\
\hline \multirow{4}{*}{$0.7 * 0.01$} & 27 & $33,768,890$ & 0.020 & $33,410,860$ & 98.93 & \\
\hline & 28 & $33,056,345$ & 0.019 & $32,566,915$ & 98.50 & 3.036 \\
\hline & 29 & $32,898,985$ & 0.013 & $32,519,485$ & 98.83 & \\
\hline & 30 & $33,173,460$ & 0.009 & $32,408,030$ & 97.64 & \\
\hline & 27 & $33,659,265$ & 0.018 & $33,410,860$ & 99.26 & \\
\hline $0.7 * 0.02$ & 28 & $33,045,945$ & 0.020 & $32,566,915$ & 98.53 & 3.031 \\
\hline & 29 & $32,941,010$ & 0.014 & $32,519,485$ & 98.70 & \\
\hline & 30 & $33,161,550$ & 0.009 & $32,408,030$ & 97.67 & \\
\hline
\end{tabular}


TABle 6: Continued.

\begin{tabular}{|c|c|c|c|c|c|c|}
\hline$R_{c} * R_{m}$ & Production time (day) & Total cost by MOGA & $C_{v}$ & Total cost by BFM & Accuracy $(\%)$ & Average computation time (sec) \\
\hline \multirow{4}{*}{$0.7 * 0.03$} & 27 & $33,644,265$ & 0.016 & $33,410,860$ & 99.30 & \multirow{4}{*}{3.031} \\
\hline & 28 & $33,203,965$ & 0.020 & $32,566,915$ & 98.04 & \\
\hline & 29 & $33,022,990$ & 0.015 & $32,519,485$ & 98.45 & \\
\hline & 30 & $33,087,065$ & 0.012 & $32,408,030$ & 97.90 & \\
\hline \multirow{4}{*}{$0.7 * 0.04$} & 27 & $33,683,865$ & 0.021 & $33,410,860$ & 99.18 & \multirow{4}{*}{3.029} \\
\hline & 28 & $33,045,945$ & 0.015 & $32,566,915$ & 98.53 & \\
\hline & 29 & $33,055,020$ & 0.014 & $32,519,485$ & 98.35 & \\
\hline & 30 & $33,333,480$ & 0.007 & $32,408,030$ & 97.14 & \\
\hline \multirow{4}{*}{$0.7 * 0.05$} & 27 & $33,644,265$ & 0.014 & $33,410,860$ & 99.30 & \multirow{4}{*}{3.030} \\
\hline & 28 & $33,203,965$ & 0.017 & $32,566,915$ & 98.04 & \\
\hline & 29 & $32,779,985$ & 0.016 & $32,519,485$ & 99.20 & \\
\hline & 30 & $33,170,355$ & 0.009 & $32,408,030$ & 97.65 & \\
\hline \multirow{4}{*}{$0.6 * 0.01$} & 27 & $33,659,265$ & 0.013 & $33,410,860$ & 99.26 & \multirow{4}{*}{2.605} \\
\hline & 28 & $32,838,715$ & 0.012 & $32,566,915$ & 99.17 & \\
\hline & 29 & $32,975,995$ & 0.012 & $32,519,485$ & 98.60 & \\
\hline & 30 & $33,466,585$ & 0.007 & $32,408,030$ & 96.73 & \\
\hline \multirow{4}{*}{$0.6 * 0.02$} & 27 & $33,904,890$ & 0.021 & $33,410,860$ & 98.52 & \multirow{4}{*}{2.604} \\
\hline & 28 & $33,085,945$ & 0.018 & $32,566,915$ & 98.41 & \\
\hline & 29 & $32,559,485$ & 0.019 & $32,519,485$ & 99.88 & \\
\hline & 30 & $32,858,030$ & 0.014 & $32,408,030$ & 98.61 & \\
\hline \multirow{4}{*}{$0.6 * 0.03$} & 27 & $33,649,365$ & 0.018 & $33,410,860$ & 99.29 & \multirow{4}{*}{2.603} \\
\hline & 28 & $32,833,315$ & 0.020 & $32,566,915$ & 99.18 & \\
\hline & 29 & $33,075,020$ & 0.015 & $32,519,485$ & 98.29 & \\
\hline & 30 & $33,156,050$ & 0.009 & $32,408,030$ & 97.69 & \\
\hline \multirow{4}{*}{$0.6 * 0.04$} & 27 & $33,668,865$ & 0.011 & $33,410,860$ & 99.23 & \multirow{4}{*}{2.605} \\
\hline & 28 & $33,096,345$ & 0.016 & $32,566,915$ & 98.37 & \\
\hline & 29 & $32,779,985$ & 0.015 & $32,519,485$ & 99.20 & \\
\hline & 30 & $33,395,860$ & 0.006 & $32,408,030$ & 96.95 & \\
\hline \multirow{4}{*}{$0.6 * 0.05$} & 27 & $33,649,365$ & 0.021 & $33,410,860$ & 99.29 & \multirow{4}{*}{2.605} \\
\hline & 28 & $33,126,935$ & 0.019 & $32,566,915$ & 98.28 & \\
\hline & 29 & $33,135,420$ & 0.017 & $32,519,485$ & 98.11 & \\
\hline & 30 & $32,878,960$ & 0.012 & $32,408,030$ & 98.55 & \\
\hline \multirow{4}{*}{$0.5 * 0.01$} & 27 & $33,410,860$ & 0.021 & $33,410,860$ & 100.00 & \multirow{4}{*}{2.175} \\
\hline & 28 & $32,973,440$ & 0.021 & $32,566,915$ & 98.75 & \\
\hline & 29 & $32,974,905$ & 0.016 & $32,519,485$ & 98.60 & \\
\hline & 30 & $32,854,560$ & 0.013 & $32,408,030$ & 98.62 & \\
\hline \multirow{4}{*}{$0.5 * 0.02$} & 27 & $33,644,265$ & 0.011 & $33,410,860$ & 99.30 & \multirow{4}{*}{2.178} \\
\hline & 28 & $33,085,945$ & 0.021 & $32,566,915$ & 98.41 & \\
\hline & 29 & $32,519,485$ & 0.016 & $32,519,485$ & 100.00 & \\
\hline & 30 & $33,191,450$ & 0.012 & $32,408,030$ & 97.58 & \\
\hline \multirow{4}{*}{$0.5 * 0.03$} & 27 & $33,697,660$ & 0.024 & $33,410,860$ & 99.14 & \\
\hline & 28 & $32,833,315$ & 0.018 & $32,566,915$ & 99.18 & 2178 \\
\hline & 29 & $33,171,910$ & 0.015 & $32,519,485$ & 97.99 & \\
\hline & 30 & $32,838,960$ & 0.012 & $32,408,030$ & 98.67 & \\
\hline & 27 & $33,644,265$ & 0.020 & $33,410,860$ & 99.30 & \\
\hline $0.5 * 0.04$ & 28 & $33,096,345$ & 0.018 & $32,566,915$ & 98.37 & 2.179 \\
\hline & 29 & $33,075,020$ & 0.014 & $32,519,485$ & 98.29 & \\
\hline & 30 & $33,065,060$ & 0.010 & $32,408,030$ & 97.97 & \\
\hline
\end{tabular}


TABLE 6: Continued.

\begin{tabular}{ccccccc}
\hline$R_{c} * R_{m}$ & Production time (day) & Total cost by MOGA & $C_{v}$ & Total cost by BFM & Accuracy (\%) & Average computation time (sec) \\
\hline \multirow{6}{*}{$0.5 * 0.05$} & 27 & $33,682,660$ & 0.018 & $33,410,860$ & 99.19 & 2.18 \\
& 28 & $32,572,315$ & 0.022 & $32,566,915$ & 99.98 & 99.26 \\
\hline
\end{tabular}

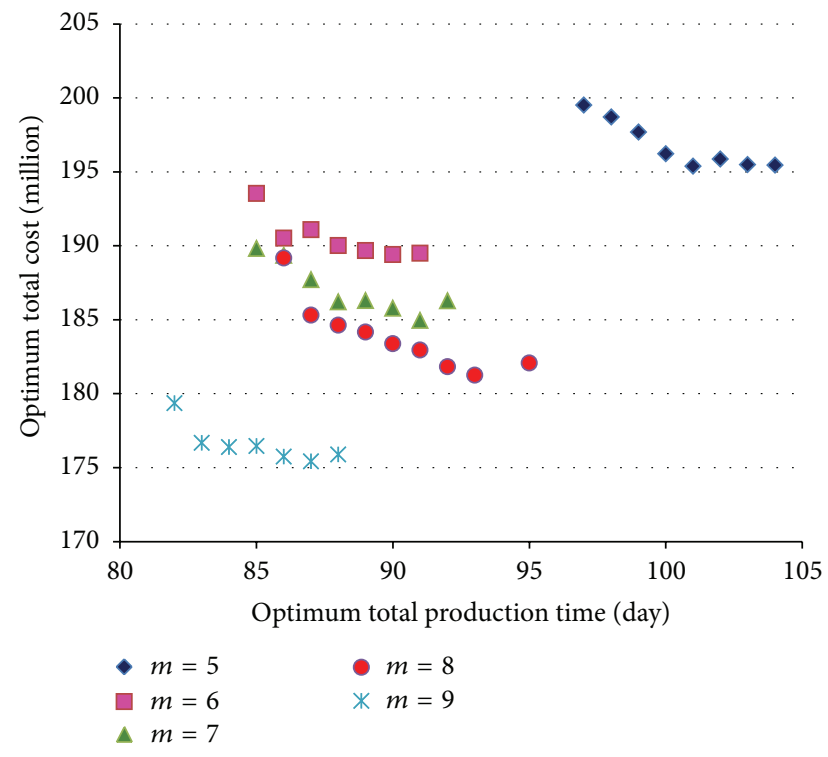

FIGURE 9: Variations of the optimal total costs and total production times with the number of plants.

cost, this way can be chosen. On the contrary, if they hope to get the minimum production time, the way in the left side can be chosen: the smaller the division number is, the shorter the production time is. If there is no division process, although it can enable the total cost to be lower, it prevents the capacity to be fully used and thus results in a low utilization rate. The division process increases the cost but enhances capacity utilization.

Some good and interesting questions might come up as a result of order division process. The first one is "should the same products produced at different manufacturing sites be gathered again before delivery?" In practice, not a few global companies prefer to deliver products directly from the manufacturing sites to the destinations. Since the contexts discussed in this paper occur in the environment of businessto-business (B2B) commerce, the destinations are usually fixed in a period of time. Direct shipment from different sites can not only reduce the transportation costs, but also shorten the delivery time. Another question is concerned with the additional shipping cost caused by the order division process. Since the division process occurs only on orders with huge amounts, the influence is very likely to be small. Even if the shipping cost is increased, minimizing the total cost can benefit the company as a whole.

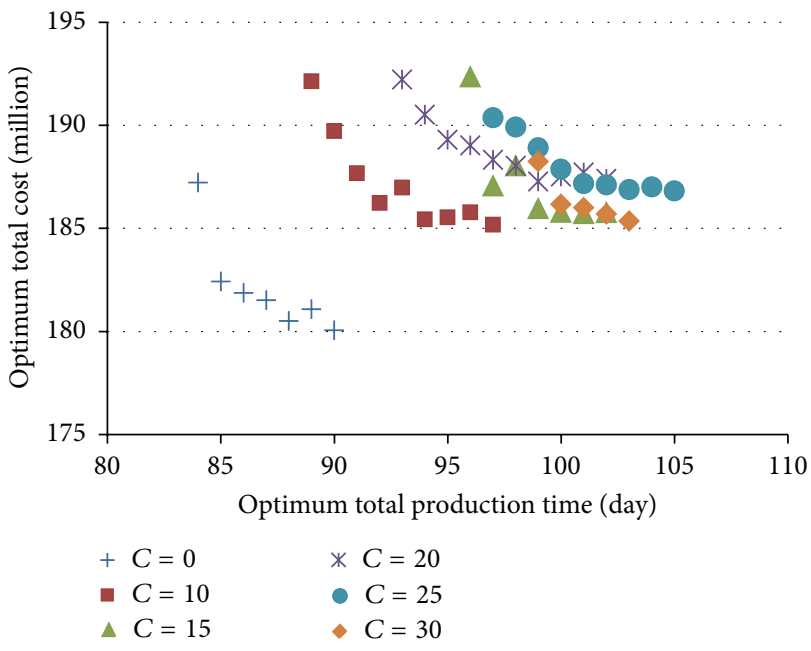

FIgUre 10: Changes in the minimum total cost and shortest total production time of each division number $(C=0$, nondivision; $C=$ 10 , division number is $10, \ldots, C=30$, division number is 30 ).

4.4. Assignment and Reassignment. As time proceeds, new orders will be released. How to deal with new incoming orders is an important issue for managers. In this paper, we reassign the new incoming orders on a rolling time basis [12], as illustrated in Figure 11. At time $t_{1}$, new orders are released. At this time, some previous orders are completed, while orders are in process. The unfinished orders will be kept in process and the rest will be rescheduled (reassigned).

For easy reassignment, a visualized system is developed. The results of assignment and reassignment are shown in Figures 12(a) and 12(b).

The visualized system developed by this study is easy to use. It is very convenient for users to change, cancel, or move the orders. If the managers are not satisfied with the assignment result, they can draw the mouse cursor onto the selected orders and move them to the desired locations. Managers can also cancel an order easily, as shown in Figure 13.

\section{Conclusions}

This paper employs multiobjective genetic algorithm (MOGA) as an analytical tool to investigate the order assignment issue for global companies with multiple plants around the world. MOGA is used to deal with order 


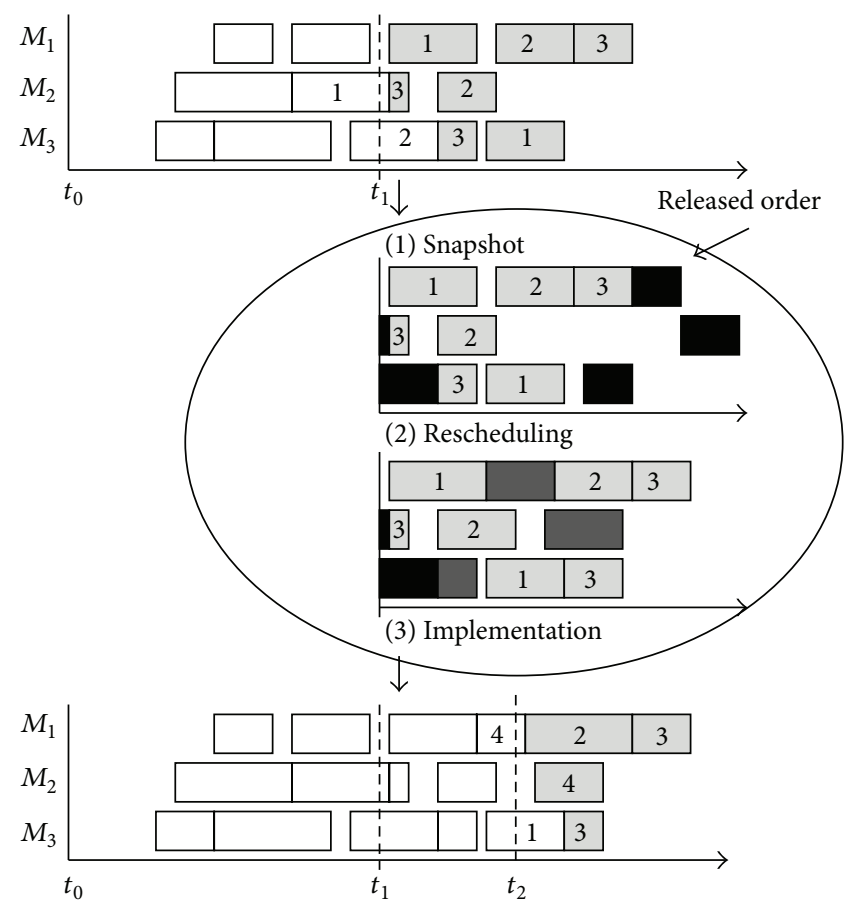

FIGURE 11: Orders are assigned and reassigned on a rolling time basis [12].

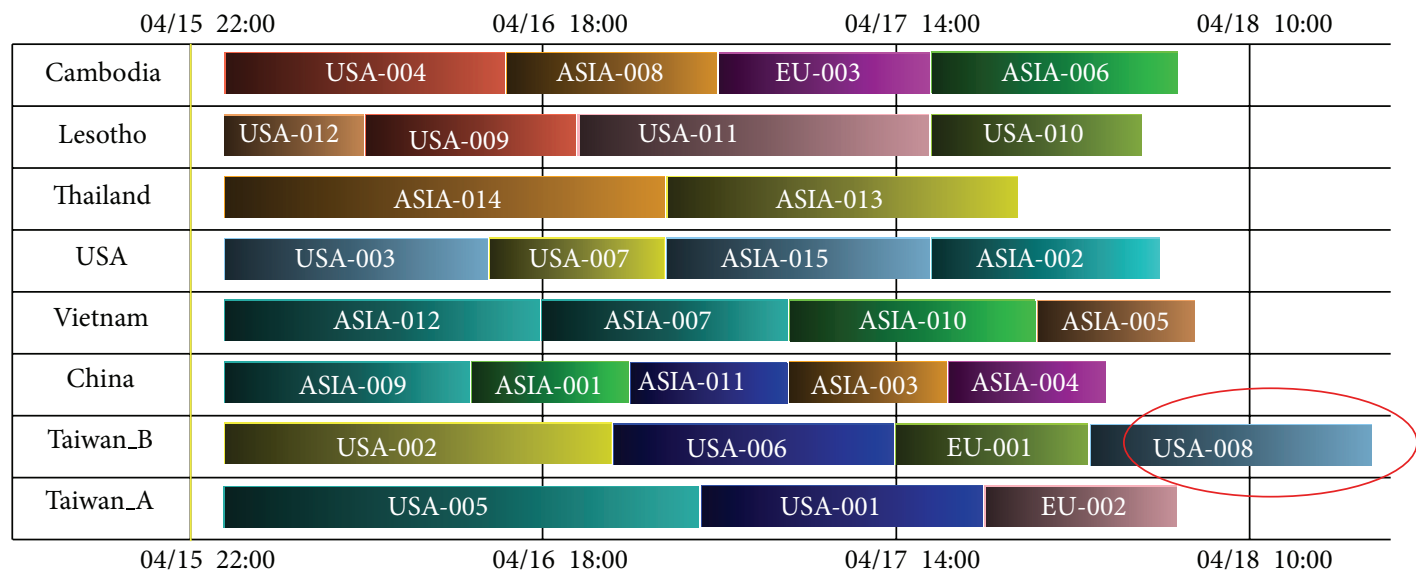

(a)

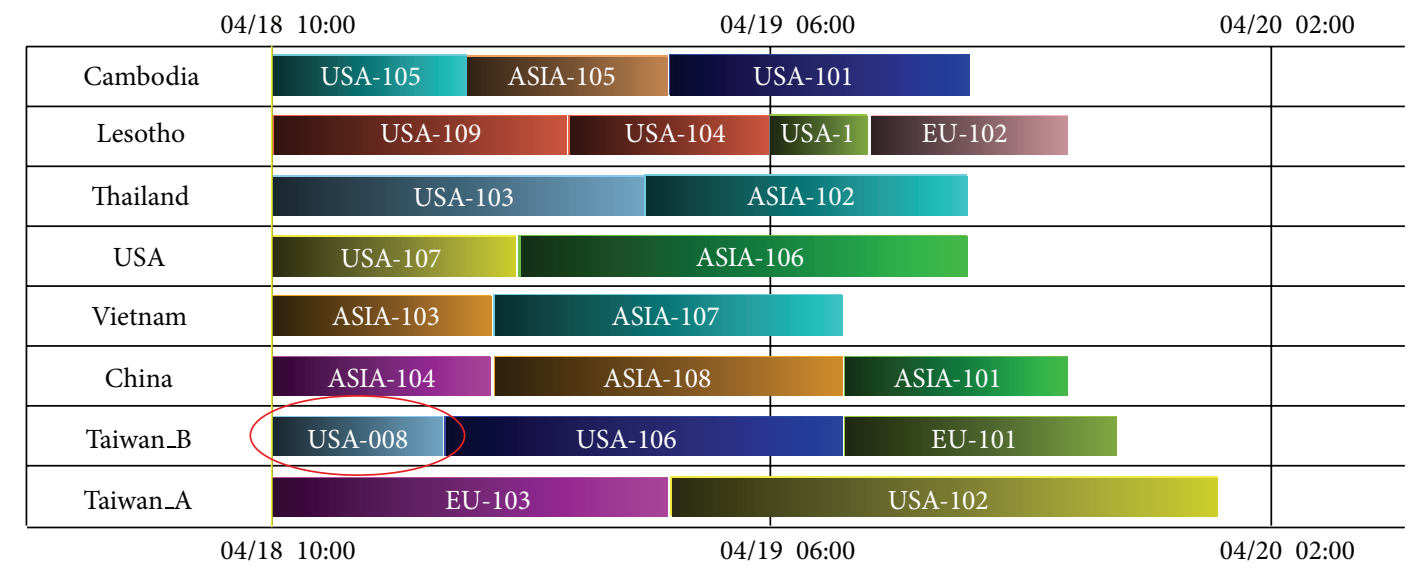

(b)

FIgUre 12: (a) The assignment result. The MO USA-008 is unfinished at time 04/18 10:00. (b) The reassignment result. Note that the MO USA-008 is fixed and the new coming MOs are reassigned. 


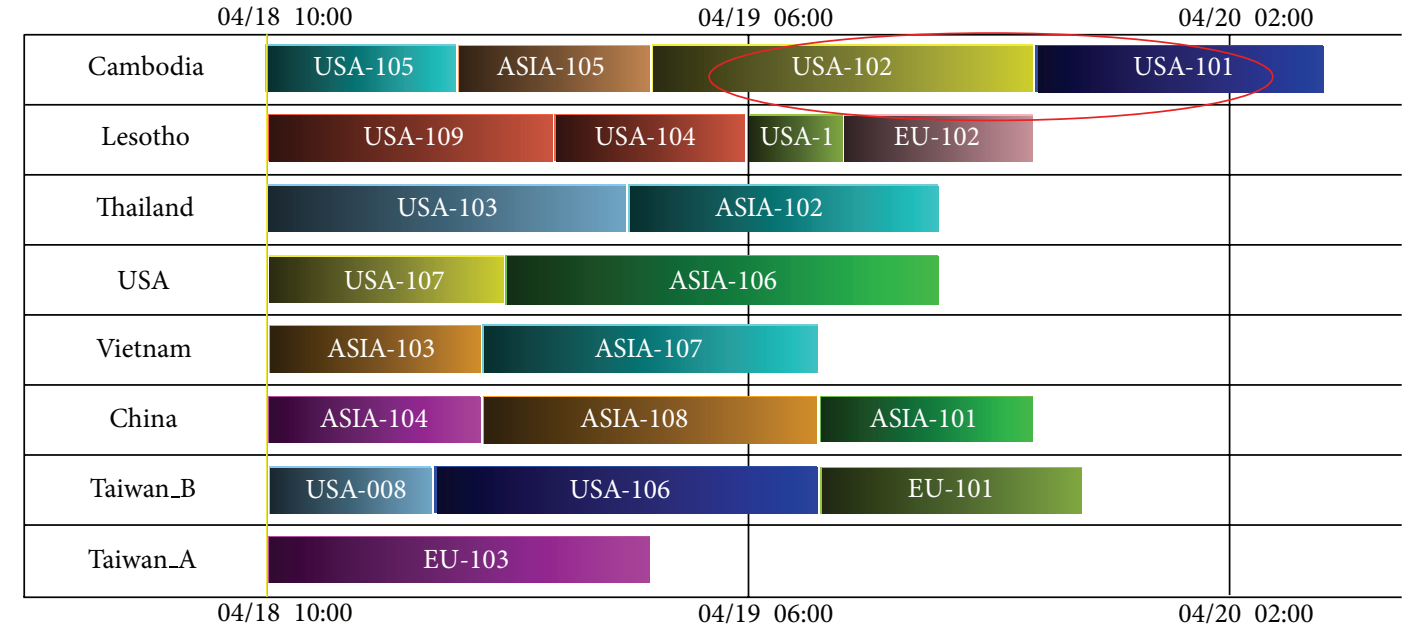

FIgURE 13: The system makes it easy to move or change orders. MO USA-102 was moved from the site in Taiwan A to the site in Cambodia, as compared with Figure 12(b).

assignment under the objectives of the lowest total cost and shortest total production time. To investigate the effectiveness of the proposed approach, this study uses a famous garment company's real data as a base to perform some experiments. This study also discusses the influences caused by a wide range of order amount demanded. Results from this study show that good workable solutions are obtainable efficiently. When it comes to orders with a wide range of changes in quantity, if managers consider the lowest total cost, they can choose solutions with larger division numbers; on the contrary, if they hope the production time is the shortest, they can choose the ones with smaller division numbers.

There are several suggestions for further studies in the future. This study makes some assumptions for the reduction of complexity. In reality, many uncertain factors, such as cancellation of order, rush order, material shortage and political factors, will cause certain plants to be unable to produce. One possible solution is to introduce autonomous control, that is, to allow some parts of a large network to make their own decisions based on local situations and available information [22, 23]. Studies may also combine MOGA with other methods. In addition, real data in other industries can be collected to perform more experiments to help further understand the differences between different industry sectors.

\section{Abbreviations}

Superscripts

\author{
DELAY: Delayed delivery \\ DELIV: Delivery \\ FG: $\quad$ Finished goods \\ MANU: Manufacturing or production \\ RM: Raw material.
}

\section{Subscripts}

$h$ : $\quad h$ th destination

$i: \quad i$ th $\mathrm{MO}$

$j: \quad j$ th material

$k$ : $\quad k$ th Manufacturing site

$c_{i}^{\text {DELAY }}$ : The penalty cost per day of the $i$ th order caused by delayed delivery

$c_{k}^{\mathrm{MANU}}$ : The unit manufacturing cost of site $k$

$c_{j}^{\mathrm{RM}}$ : The unit material cost of raw material $j$

$c_{k h}^{\text {DELIV }}$ : The unit delivery cost from site $k$ to destination $h$

C: $\quad$ The number of smaller orders; the larger order was divided into groups of $C$

$D_{i}$ : The delayed days of the $i$ th order

$Q_{i}: \quad$ The quantity of the $i$ th $\mathrm{MO}$

$Q_{i}^{\mathrm{FG}}: \quad$ The quantity of finished goods of $i$ th $\mathrm{MO}$

$Q_{i h}^{\mathrm{FG}}$ : The quantity of finished goods of $i$ th MO delivered to destination $h$

$Q_{i j}^{\mathrm{RM}}: \quad$ The quantity of the $i$ th raw material of $i$ th $\mathrm{MO}$,

$m: \quad$ The number of factories

$n: \quad$ The number of manufacturing orders

$S_{i}: \quad$ The required capacity of $\mathrm{MO} i$

$S_{k}$ : The capacity of the $k$ th site

$z_{k h}: \quad 0-1$ variable; $z_{k h}=1$ if site $k$ delivers products to destination $h$; otherwise, $z_{k h}=0$.

\section{Conflict of Interests}

The authors declare that there is no conflict of interests regarding the publication of this paper. 


\section{Acknowledgments}

The authors would like to express their sincere thanks to three anonymous reviewers who provided valuable input to substantially improve this paper. This work was supported partly by the National Science Council under Grants 1022221-E-025-013 and 98-2622-E-025-002-CC3. Thanks are also extended to Dr. Chih-Chiang Lin, Ms. Nancy D. Wall, Ms. Mei-Ching Wu, Ms. Yu-Ying Chou, Ms. Nuo-Jhen Ma, and Ms. Mei-Hui Wu for their help during the course of this paper.

\section{References}

[1] Z.-L. Chen and G. Pundoor, "Order assignment and scheduling in a supply chain," Operations Research, vol. 54, no. 3, pp. 555$572,2006$.

[2] Z. X. Guo, W. K. Wong, Z. Li, and P. Ren, "Modeling and Pareto optimization of multi-objective order scheduling problems in production planning," Computers and Industrial Engineering, vol. 64, no. 4, pp. 972-986, 2013.

[3] P. P. Dornier, R. Ernst, M. Fender, and P. Kouvelis, Global Operations and Logistics: Text and Cases, John Wiley \& Sons, New York, NY, USA, 2008.

[4] R. C. Chen and T. T. Hu, "A decision-making mechanism considering carbon footprint and cost to fulfill orders for multisite global companies," to appear in International Journal of Shipping and Transport Logistics.

[5] S. Chopra and P. Meindl, Supply Chain Management: Strategy, Planning, and Operation, Prentice Hall, Upper Saddle River, NJ, USA, 2012.

[6] B. Błażewicza, W. Domschke, and E. Pesch, "The job shop scheduling problem: conventional and new solution techniques," European Journal of Operational Research, vol. 93, no. 1, pp. 1-33, 1996.

[7] J. H. Holland, Adaptation in Natural and Artificial Systems, MIT Press, Cambridge, Mass, USA, 1975.

[8] D. E. Goldberg, Genetic Algorithm in Search, Optimization, and Machine Learning, Addison-Wesley, Boston, Mass, USA, 1989.

[9] M. Gen, R. Cheng, and L. Lin, Network Models and Optimization: Multi-Objective Genetic Algorithm Approach, Springer, Heidelberg, Germany, 2008.

[10] R. C. Chen, "Grouping optimization based on social relationships," Mathematical Problems in Engineering, vol. 2012, Article ID 170563, 19 pages, 2012.

[11] R. C. Chen, M. R. Huang, R. G. Chung, and C. J. Hsu, "Allocation of short-term jobs to unemployed citizens amid the global economic downturn using genetic algorithm," Expert Systems with Applications, vol. 38, no. 6, pp. 7535-7543, 2011.

[12] C. Bierwirth and D. C. Mattfeld, "Production scheduling and rescheduling with genetic algorithms," Evolutionary Computation, vol. 7, no. 1, pp. 1-17, 1999.

[13] R. Bhatnagar, P. Chandra, and S. K. Goyal, "Models for multiplant coordination," European Journal of Operational Research, vol. 67, no. 2, pp. 141-160, 1993.

[14] K. K. Yang and C. C. Sum, "A comparison of job shop dispatching rules using a total cost criterion," International Journal of Production Research, vol. 32, no. 4, pp. 807-820, 1994.

[15] E. Zitzler and L. Thiele, "Multiobjective evolutionary algorithms: a comparative case study and the strength Pareto approach," IEEE Transactions on Evolutionary Computation, vol. 3, no. 4, pp. 257-271, 1999.

[16] D. Özgen, S. Önüt, B. Gülsün, U. R. Tuzkaya, and G. Tuzkaya, "A two-phase possibilistic linear programming methodology for multi-objective supplier evaluation and order allocation problems," Information Sciences, vol. 178, no. 2, pp. 485-500, 2008.

[17] R. C. Chen, S. S. Li, C. C. Lin, and C. C. Feng, "A GA-based global decision support system for garment production," in Proceedings of the IEEE International Conference on Neural Networks and Brain (ICNNB '05), vol. 2, pp. 805-809, Beijing, China, October 2005.

[18] R. C. Chen, S. S. Li, C. C. Lin, and T. S. Chen, "Application of selfadaptive genetic algorithm on allocating international demand to global production facilities," in Proceedings of the 6th World Congress on Intelligent Control and Automation (WCICA '06), pp. 7152-7156, Dalian, China, June 2006.

[19] R. C. Chen, C. H. Chen, and P. H. Hung, "Product miles as an objective to assign orders in a globally multiple plant environment," Advanced Science Letters, vol. 19, no. 8, pp. 22312235, 2013

[20] P. R. Harper, V. de Senna, I. T. Vieira, and A. K. Shahani, "A genetic algorithm for the project assignment problem," Computers and Operations Research, vol. 32, no. 5, pp. 12551265, 2005.

[21] C. M. Fonseca and P. J. Fleming, "Genetic algorithms for multiobjective optimization: formulation, discussion and generalization," in Proceedings of the 5th International Conference on Genetic Algorithms (ICGA '93), pp. 416-423, Morgan Kaufmann Publishers, Urbana-Champaign, Ill, USA, 1993.

[22] H. R. Karimi, N. A. Duffie, and S. Dashkovskiy, "Local capacity $H_{\infty}$ control for production networks of autonomous work systems with time-varying delays," IEEE Transactions on Automation Science and Engineering, vol. 7, no. 4, pp. 849-857, 2010.

[23] S. Dashkovskiy, M. Görges, and L. Naujok, "Autonomous control methods in logistics-a mathematical perspective," Applied Mathematical Modelling, vol. 36, no. 7, pp. 2947-2960, 2012. 


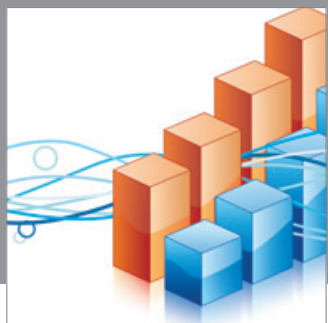

Advances in

Operations Research

mansans

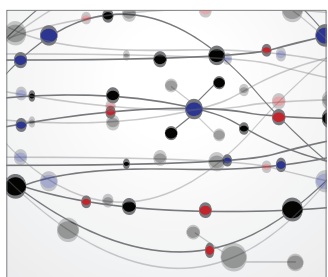

The Scientific World Journal
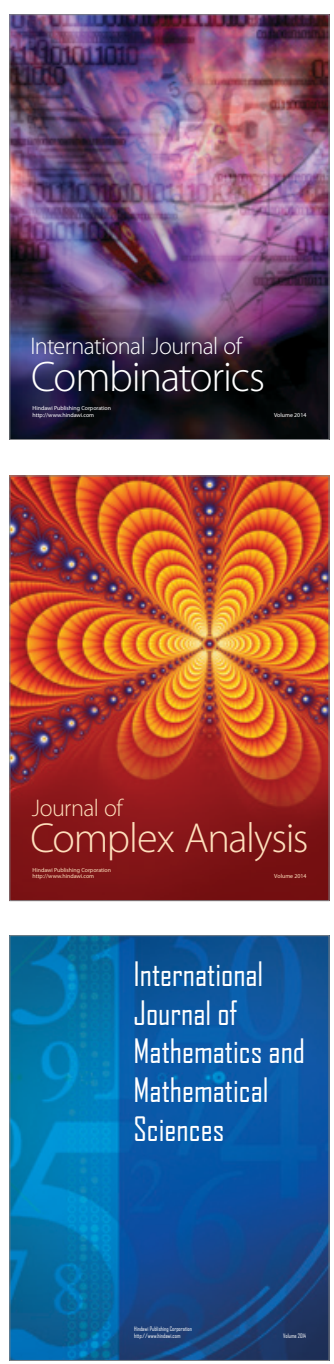
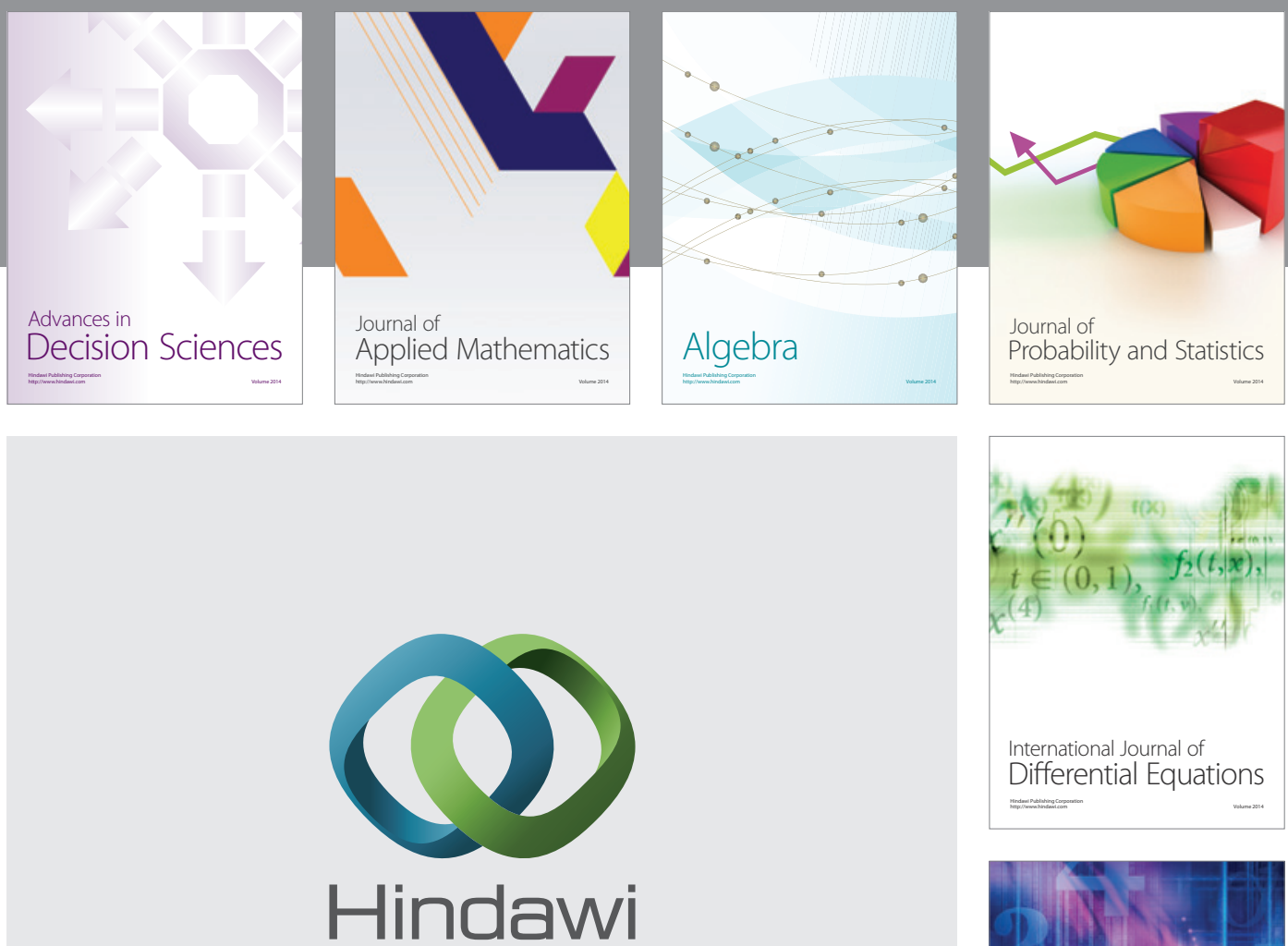

Submit your manuscripts at http://www.hindawi.com
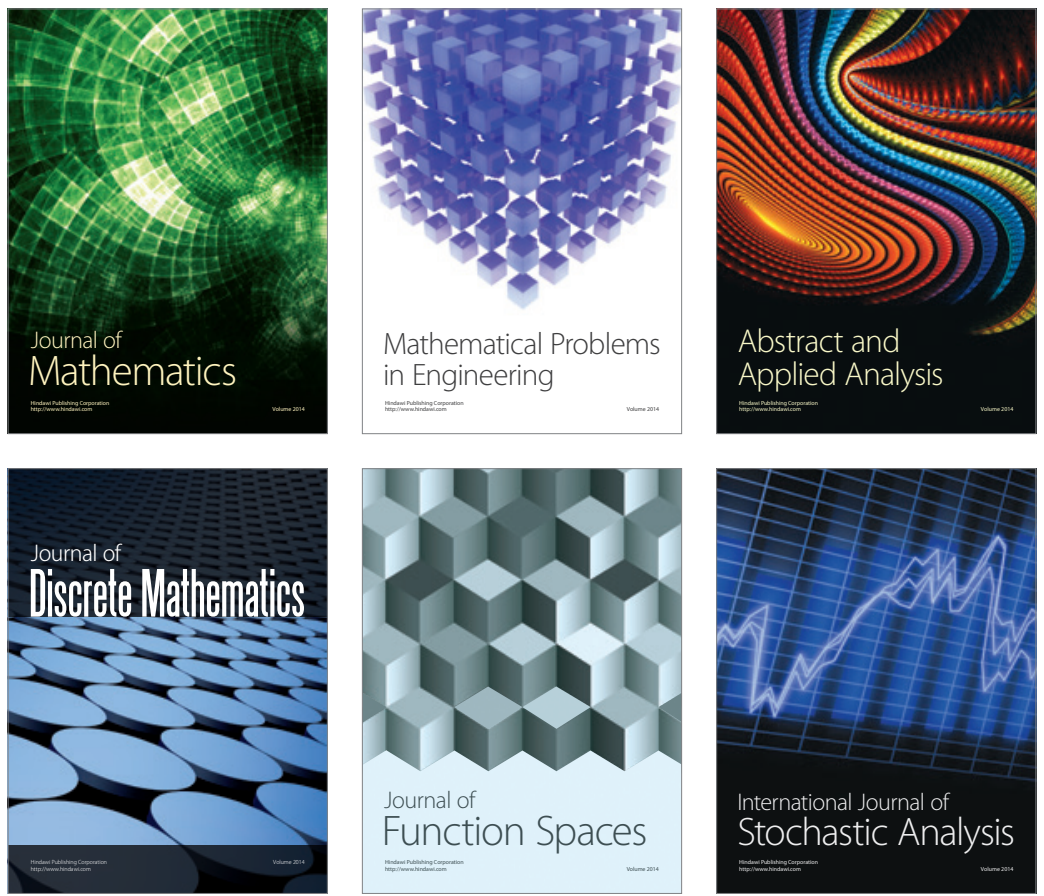

Journal of

Function Spaces

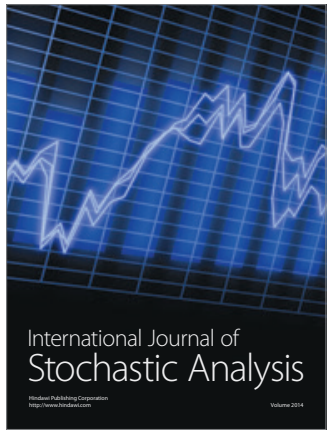

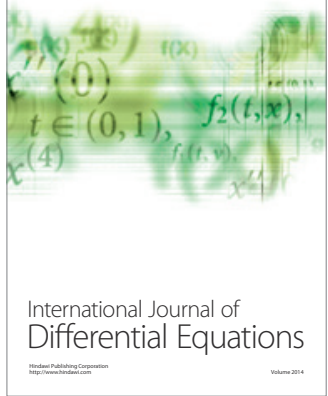
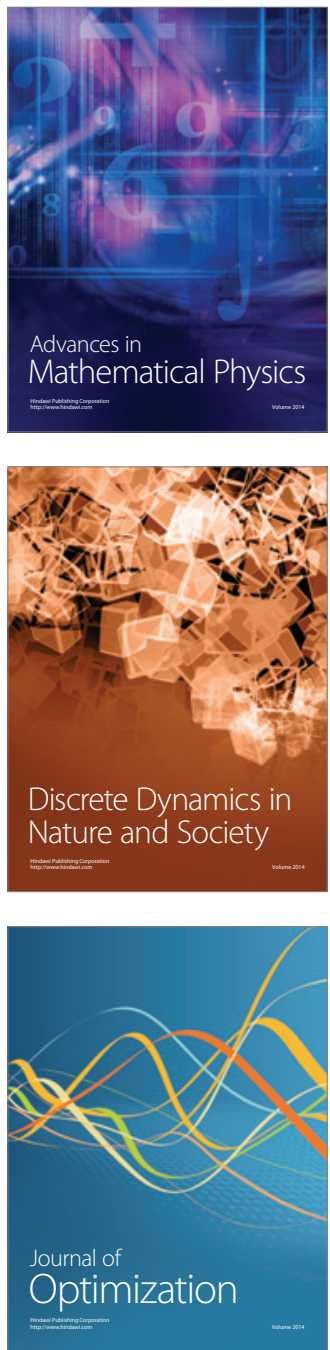